\title{
"Commercial pressures and professional ethics: troubling revisions to the recent ACOG Practice Bulletins on surgery for pelvic organ prolapse": response to Weber
}

\author{
L. Lewis Wall • Douglas Brown
}

Received: 31 August 2009 /Accepted: 4 September 2009 /Published online: 25 September 2009

(C) The International Urogynecological Association 2009

We thank Dr. Weber [1] for her interest in our article [2]. We are deeply saddened by her detailed confirmation of our worst suspicions concerning the removal of any reference to the 'experimental' nature of the trocar-and-mesh kit operations for prolapse in ACOG Practice Bulletin \#85. We agree with her that the original wording should be restored. We further suggest that ACOG affirm in print its commitment to promoting evidence-based practice that is truly in the best interests of patients, even if doing so potentially threatens the financial interests of members of the College.

\section{References}

1. Weber A (2009) Response to Wall and Brown: "Commercial pressures and professional ethics: troubling revisions to the recent ACOG Practice Bulletins on surgery for pelvic organ prolapse". Int Urogynecol J doi:10.1007/s00192-009-0985-8

2. Wall LL, Brown D (2009) Commercial pressures and professional ethics: troubling revisions to the recent ACOG practice bulletins on surgery for pelvic organ prolapse. Int Urogynecol J 20:765-767. doi:10.1007/s00192-009-0864-3

Related correspondence can be found at doi:10.1007/s00192-009-0983-x and doi:10.1007/s00192-009-0984-9

L. L. Wall $(\bowtie)$

Obstetrics \& Gynecology, Washington University St. Louis,

Campus Box 8064, WUSM 660 South Euclid Avenue,

Saint Louis, MO 63110, USA

e-mail: WALLL@wustl.edu

D. Brown

Barnes-Jewish Hospital Ethics Program, Barnes-Jewish Hospital,

St. Louis, MO, USA

e-mail: ddb4677@bjc.org 